Full length article

\title{
Protective effect of antigen delivery using monoolein-based liposomes in experimental hematogenously disseminated candidiasis
}

\author{
Catarina Carneiro a ${ }^{\text {, Alexandra Correia }}{ }^{\mathrm{b}, \mathrm{c}}$, Tânia Lima ${ }^{\mathrm{a}}$, Manuel Vilanova ${ }^{\mathrm{b}, \mathrm{c}, \mathrm{d}}$, Célia Pais ${ }^{\mathrm{a}}$, \\ Andreia C. Gomes ${ }^{\mathrm{a}, \mathrm{f}}$, M. Elisabete C.D. Real Oliveira ${ }^{\mathrm{e}, \mathrm{f}}$, Paula Sampaio ${ }^{\mathrm{a}, *}$ \\ ${ }^{a}$ Centre of Molecular and Environmental Biology (CBMA), Department of Biology, University of Minho, 4710-057 Braga, Portugal \\ ${ }^{\mathrm{b}}$ Instituto de Investigação e Inovação em Saúde, Universidade do Porto, 4150-180 Porto, Portugal \\ ' IBMC - Instituto de Biologia Molecular e Celular, Universidade do Porto, 4150-180 Porto, Portugal \\ ${ }^{\mathrm{d}}$ Instituto de Ciências Biomédicas de Abel Salazar (ICBAS), Universidade do Porto, Rua de Jorge Viterbo Ferreira n. ${ }^{\circ} 228,4050-313$ Porto, Portugal \\ ${ }^{\mathrm{e}}$ Centre of Physics (CFUM) University of Minho, Campus of Gualtar, 4710-057 Braga, Portugal \\ ${ }^{\mathrm{f}}$ NanoDelivery IED in Biotecnology, Biology Department, Campus of Gualtar, 4710-057 Braga, Portugal
}

\section{A R T I C L E I N F O}

\section{Article history:}

Received 13 November 2015

Received in revised form 22 April 2016

Accepted 1 May 2016

Available online 2 May 2016

\section{Keywords:}

DODAB:MO liposomes

Nanoparticles

Antigen delivery systems

Candida albicans proteins

Dendritic cells

Humoral and cellular immune responses

\begin{abstract}
A B S T R A C T
We evaluated the potential of a liposomal antigen delivery system (ADS) containing Candida albicans cell wall surface proteins (CWSP) in mediating protection against systemic candidiasis. Treatment of bonemarrow-derived dendritic cells with CWSP-loaded dioctadecyldimethylammonium bromide:monoolein (DODAB:MO) liposomes enhanced and prolonged their activation comparatively to free antigen, indicating that liposome-entrapped CWSP were released more sustainable. Therefore, we immunized mice with CWSP either in a free form or loaded into two different DODAB:MO liposome formulations, respectively designated as ADS1 and ADS2, prior to intravenous C. albicans infection. Immunization with ADS1, but not with ADS2, conferred significant protection to infected mice, comparatively to immunization with CWSP or empty liposomes as control. ADS1-immunized mice presented significantly higher serum levels of $C$. albicans-specific antibodies that enhanced phagocytosis of this fungus. In these mice, a mixed cytokine production profile was observed encompassing IFN- $\gamma$, IL-4, IL-17A and IL-10. Nevertheless, only production of IL-4, IL-17 and IL-10 was higher than in controls. In this study we demonstrated that DODAB:MO liposomes enhance the immunogenicity of $C$. albicans antigens and host protection in a murine model of systemic candidiasis. Therefore, this liposomal adjuvant could be a promising candidate to assess in vaccination against this pathogenic fungus.
\end{abstract}

\section{Statement of Significance}

This work describes the immunomodulation capacity of the previously validated antigen delivery system (ADS) composed by dioctadecyldimethylammonium bromide (DODAB) and monoolein (MO) lipids incorporating the cell wall surface proteins (CWSP) from C. albicans. Here, we not only present the ability of this system in facilitating antigen uptake by DCs in vitro, but also that this system induces higher levels of pro-inflammatory cytokines and opsonizing specific IgG antibodies in serum of mice immunized subcutaneously. We show that the ADS are efficient nanocarrier and modulate the immune response against intravenous $C$. albicans infection favoring mouse protection. In sum, we show that the incorporation of $C$. albicans antigens in DODAB:MO nanocarries are a promising vaccine strategy against $C$. albicans fungal infection.

(c) 2016 Acta Materialia Inc. Published by Elsevier Ltd. All rights reserved.
* Corresponding author at: University of Minho, Campus of Gualtar, 4710-057 Braga, Portugal.

E-mail address: psampaio@bio.uminho.pt (P. Sampaio).

\section{Introduction}

Vaccines are routinely used to protect against microbial pathogens. They usually contain antigens as surrogates of the diseasecausing microorganism or a product of it. Antigens may include weakened or inactivated forms of the target pathogen, or subunits 
that could be constitutive or extracellular molecules [1]. Nevertheless, the use of attenuated pathogens raises several safety issues due to possible reversion of the phenotype or residual virulence. These safety problems may be circumvented by using subunit vaccines. In such case, univalent subunit vaccines may have their effectiveness limited due to antigen variations in the target pathogens. The use of complex antigen extracts, instead of single molecules, in the immunogenic preparations may be a way to overcome this issue [2]. Yet, the effective implementation of subunit vaccines is frequently impaired by insufficient immunogenicity when administered without adjuvant [3,4]. Therefore, selecting an appropriate adjuvant or delivery system is as important as selecting antigen candidates.

Formulating protein antigens into nanoparticles has emerged as one of the most promising strategies to enhance the immune response to vaccine antigens [5-9]. Cationic liposomes are interesting adjuvants that also serve as carriers for the targeted delivery of antigens to immune cells. These liposomes tightly bind negatively charged antigens, which may render soluble antigens into a particulate form thereby increasing their in vivo half-life $[7,9]$. In fact, cationic liposomes were used as adjuvants in several studies, enhancing cell mediated or humoral immunity, as well as delivery systems for drugs, DNA or peptides $[5,6,10]$. Major limitations behind the fact that as yet no adjuvant based on liposomes has been registered for human use seem to be their stability, manufacturing and quality assurance problems [11]. However, these limitations may be overcome by tuning physicochemical properties like size, charge and hydrophobicity [12-14]. Recently, a direct comparative study showed that cationic liposomes were most efficient for the induction of effector antigen-specific T cells in vivo, than poly-(lactic-coglycolic-acid) (PLGA) nanoparticles or the clinically used adjuvants Montanide ISA-51 and SWE, a squalene oilin-water emulsion [13].

Cationic liposomes composed by surfactant dioctadecyldimethylammonium bromide (DODAB) have been used as carriers in drug delivery studies $[8,15]$ as well as adjuvants in vaccination strategies, displaying higher colloidal stability than aluminum hydroxide and better efficacy in inducing cellular immune responses [16-18]. The main advantage of DODAB as an adjuvant is that it requires a lipid concentration lower than the concentrations traditionally used in liposomal formulations $[19,20]$. However, these preparations can be physically unstable and therefore the incorporation of different neutral molecules, such as cholesterol, 1-monopalmitoyl glycerol and trehalose 6,60-dibehenate have shown to improve the stability without undermining their adjuvanticity [21]. In previous studies we have demonstrated that monoolein (MO), when incorporated as helper lipid with DODAB, could act as a stabilizer, conferring fluidity to the DODAB nanoparticle liposomes by favoring lipid chain mobility [22]. We have successfully used DODAB:MO as a mammalian cell transfection system and as a nanocarrier for in vitro gene silencing $[15,23]$. In particular, we demonstrated that liposomes formed by DODAB and MO at DODAB:MO (1:2) molar ratio, assembled mainly as positively spherical bilamellar vesicles with some internal structures [24]. In this way, in a recent report, we explored this formulation, DODAB:MO (1:2), and described the development of two liposomal nanoparticle antigen delivery systems (ADS), ADS1 and ADS2, loaded with Candida albicans cell wall surface proteins (CWSP) as antigens. These ADS assembled as stable negatively charged spherical nanoparticles with an average particle size of approximately $280 \mathrm{~nm}$, indicating that the CWSP readily associated with the liposomes [25]. This efficient adsorption onto the liposomes and their size, mimicking that of natural pathogens, induced a strong, humoral and cell-mediated immunity when compared with free CWSP [26]. C. albicans is an opportunistic human pathogen and is by far the most common cause of fungal invasive infections [25]. Despite the availability of new antifungal agents, candidemia is the fourth most common bloodstream infection in hospitalized patients both in the United States and in many European countries [27-29].

Consequently, antifungal vaccines are currently considered one of the most appealing and cost effective strategies against Candida infections [27,30-32]. As far as we know, only two vaccines against C. albicans infections have completed Phase I clinical trials, the adhesin-like substance 3 (Als3) with aluminum hydroxide as the adjuvant (NDV-3; NovaDigm Therapeutics) [33], and secreted aspartic protease 2 (Sap2) embedded in a virosomal for adjuvanticity (PEV-7; Pevion Biotech) [34].

In this work, we assessed the effectiveness of the designed DODAB:MO liposomal nanoparticle associated with a C. albicans CWSP preparation in inducing protection in a mouse model of systemic candidiasis established by the hematogenous route. Our results showed that these liposomal systems induced strong opsonizing antibody responses and a cell-mediated immune response that allowed a significant protection of infected mice.

\section{Material and methods}

\subsection{Materials}

Dioctadecyldimethylammonium bromide (DODAB) was purchased from Tokyo Kasei (Japan). 1-monooleoyl-rac-glycerol (MO), Hanks' balanced salt solution (HBSS), glutaraldehyde, propidium iodide (PI) and DTT were supplied by Sigma-Aldrich (St. Louis, MO, USA). Tris- $\mathrm{HCl}$ Buffer was provided by Invitrogen/ Molecular Probes (Eugene, OR, USA) and ethanol (high spectral purity) was purchased from Uvasol (Leicester, United Kingdom). Dulbecco's Modified Eagle's Medium (DMEM) was supplemented with $2 \mathrm{mM}$ L-glutamine, (all from Sigma-Aldrich) and 10\% heatinactivated fetal bovine serum (FBS) provided by Lonz (Romania); HEPES-Buffer solution pH 7.5 was provided by VWR International (Radnor, PA, USA) and $1 \mathrm{mM}$ sodium pyruvate by Merck (Frankfurt, Germany). Sytox Green was purchased from Thermo Fisher Scientific (Massachusetts, MA, USA) and propidium iodide (PI) was obtained form Sigma-Aldrich.

\subsection{Culture conditions of $C$. albicans strains}

C. albicans strain SC5314 was used for CWSP extraction while $C$. albicans 124A clinical isolate [35] was used for infection experiments. All strains were maintained as frozen stocks in 30\% glycerol at $-80^{\circ} \mathrm{C}$. When needed, yeasts were obtained from a 2 day YPD agar plate $(2 \%$ D-glucose, $1 \%$ Difco yeast extract, $2 \%$ peptone and $2 \%$ agar) $(\mathrm{w} / \mathrm{v})$ incubated at $30{ }^{\circ} \mathrm{C}$.

\subsection{Extraction of yeast CWSP}

All procedures used for CWSP extraction were performed in a sterile environment and using apyrogenic solutions. CWSP were released from intact yeast cells by DTT treatment as described previously [26]. The concentrated proteins obtained were stored at $-80^{\circ} \mathrm{C}$ in aliquots of $100 \mu \mathrm{g} / \mathrm{ml}$.

\subsection{Preparation and characterization of CWSP-loaded liposomes}

DODAB:MO based liposomes were prepared using the lipid-film hydration method [36]. Briefly, DODAB and MO, at a DODAB molar fraction ( $\chi$ DODAB) of 0.33 , were dissolved in ethanol and mixed in a round-bottom flask. The solvent was removed by rotary evaporation, at a temperature $10^{\circ} \mathrm{C}$ above the main phase transition of DODAB $\left(\mathrm{Tm} \approx 44^{\circ} \mathrm{C}\right)$, and liposomes formed after hydration of 
the lipid film with $25 \mathrm{mM}$ HEPES pH 7.5 at $55^{\circ} \mathrm{C}$. The dispersion was then placed in a bath sonicator during $2 \mathrm{~min}$.

Two liposomal stock dispersions were prepared, stock 1, used for ADS1, at a total lipid concentration of $1774 \mu \mathrm{g} / \mathrm{ml}$ and stock 2 , used for ADS2, at a total lipid concentration of $266 \mu \mathrm{g} / \mathrm{ml}$. For the ADSs assembling, equal volumes of CWSP were added to the respective stock dispersions post lipid-film hydration. For both ADS the final concentration of CWSP was $50 \mu \mathrm{g} / \mathrm{ml}$. For ADS1, the final total lipid concentration was $888 \mu \mathrm{g} / \mathrm{ml}$ and for ADS2 was $133 \mu \mathrm{g} / \mathrm{ml}$ (Table 1 ). The empty liposomes (EL) were always used at a final total lipid concentration of $888 \mu \mathrm{g} / \mathrm{ml}$. These formulations were then incubated for $1 \mathrm{~h}$, at $55^{\circ} \mathrm{C}$, to ensure CWSP adsorption followed by a brief sonication step in a water-bath sonicator.

\subsection{Quantification of protein retention}

ADS1, ADS2 and empty liposomes were prepared as described in Section 2.4. Protein retention was evaluated at different time points, $0,3,24,48$ and $72 \mathrm{~h}$ after preparation. The prepared formulations were pelleted by ultracentrifugation $(100,000 \mathrm{~g}$ for $1 \mathrm{~h})$, the pellet submitted to TCA protein precipitation (Thermo Scientific Pierce), and the proteins quantified with the BCA Protein Assay Kit (Thermo Scientific Pierce), according to the manufacturer's instructions. Empty liposomes were used as a negative control in order to exclude lipid interference in the protein quantification method.

\subsection{Stimulation of bone marrow-derived DC (BMDC)}

Bone marrow cells were collected from femurs and tibias of female BALB/c mice by flushing with cold RPMI 1640 (Sigma). BMDC were differentiated as described by Cerca et al. [37]. Briefly, cells $\left(1 \times 10^{6} / \mathrm{mL}\right)$ were cultured in 6 -well plates in RPMI supplemented with $15 \%(\mathrm{v} / \mathrm{v})$ J558-cell supernatant, 10\% FBS penicillin (100 U.I./mL)-streptomycin $(100 \mu \mathrm{g} / \mathrm{ml})$ (Sigma), and L-glutamine (2 mM) (Sigma) and incubated at $37{ }^{\circ} \mathrm{C}$ and $5 \% \mathrm{CO}_{2}$. Half of the medium was renewed every two days. At day 8, BMDCs were detached and distributed in 96 -well round bottom plates adjusted at a concentration of $2 \times 10^{5}$ cells/well in supplemented RPMI medium. Differentiation of bone marrow precursors into BMDC was confirmed by flow cytometry assessing surface expression of CD11c, CD80, CD86 and MHC class II (Fig. S1). Immediately after being seeded, cells were stimulated with $10 \mu \mathrm{l}$ of CWPS $(0.5 \mu \mathrm{g})$, ADS1 $(0.5 \mu \mathrm{g}$ of CWSP loaded in $8.8 \mu \mathrm{g}$ of total lipid), ADS2 $(0.5 \mu \mathrm{g}$ of CWSP loaded in $1.33 \mu \mathrm{g}$ of total lipid) or EL $(8.8 \mu \mathrm{g}$ of total lipid) in a final volume of $200 \mu \mathrm{l}$. LPS ( $1 \mu \mathrm{g} / \mathrm{ml})$ (Sigma) and un-stimulated cells were used as positive and negative controls of activation, respectively. After 6 or $24 \mathrm{~h}$, the culture supernatants were removed and stored at $-80^{\circ} \mathrm{C}$. For the assessment of cell surface markers, after stimulation, the BMDC were collected from the culture plates, washed twice in Hanks's Balanced Salt Solution

Table 1

Composition, mean size and $\zeta$-potential of ADS. DODAB:MO liposomes were mixed with CWSP for $1 \mathrm{~h}$ to prepare ADS1 and ADS2. Mean size and $\zeta$-potential were measured by dynamic light scattering on a ZetaSizer NanoZS. PDI: polydispersity index.

\begin{tabular}{lllll}
\hline & ADS1 & ADS2 & CWSP & $\begin{array}{l}\text { Empty } \\
\text { liposomes }\end{array}$ \\
\hline $\begin{array}{c}\text { Total lipid }(\mu \mathrm{g} / \\
\text { ml) }\end{array}$ & 888 & 133 & - & 888 \\
$\begin{array}{c}\text { CWSP added } \\
\quad \mu \mathrm{g} / \mathrm{ml})\end{array}$ & 50 & 50 & 50 & - \\
$\begin{array}{l}\text { Mean size }(\mathrm{nm}) \\
\text { PDI }\end{array}$ & $223 \pm 37$ & $255 \pm 46$ & $88.7 \pm 5.1$ & $176.8 \pm 23$ \\
$\quad$-potential $(\mathrm{mv})$ & $-18.3 \pm 1.5$ & $-21.8 \pm 1.4$ & $-14 \pm 0.7$ & $54.6 \pm 3.2$ \\
\hline
\end{tabular}

(Sigma) and incubated with specific monoclonal antibodies (mAb). The following mAbs, along with their respective isotype controls were used (at previously determined optimal dilutions [38] for immunofluorescence cytometry: fluorescein isothiocyanate (FITC) hamster anti-mouse CD11c (HL3), phycoerythrin (PE) anti-mouse CD80 (B7-1) (16-10A1); phycoerythrin-cyanine 7 (PE-Cy7) anti-mouse CD86 (B7-2) (GL1); peridinin-chlorophyll protein (PerCp) anti-mouse I-Ad/I-Ed (clone 2G9); all from BD Biosciences Pharmingen, San Diego, CA. The analyzed cell samples were always pre-incubated with anti-Fc $\gamma \mathrm{R} \mathrm{mAb}$ before the antibody incubation to prevent non-specific antibody binding. All cytometric measurements were performed in an EPICS XL flow cytometer using the EXPO32ADC software (Beckman Coulter). The collected data files were analyzed using FLOWJO X 10.0.7r2 software.

The concentrations of IL-23, IL-12 and TNF- $\alpha$ in cell culture supernatants were quantified with the respective Mouse enzyme-linked immunosorbent assay (ELISA) Ready-Set-Go kit (eBioscience, San Diego, CA) while IL-10 was quantified using the Mouse IL-10 DuoSet ELISA development system (R\&D Systems, Minneapolis, MN); according to the manufacturer's instructions.

\subsection{Cellular delivery of proteins via $A D S$}

Confocal microscopy was performed as described before [26]. Briefly, macrophages (RAW 264.7 cell line) were plated in 6-well chamber plates (Ibidi) $3 \times 10^{5}$ cells/well and left to adhere overnight at $37{ }^{\circ} \mathrm{C}$ in a humidified atmosphere of $5 \% \mathrm{CO}_{2}$. Prior to ADS preparation, Rhodamine (Rho) DHPE (at a molar ratio of $1: 200)$ was incorporated into DODAB:MO liposomes during the preparation phase, prior to solvent removal by rotary evaporation. Before incubation with Rho-DHPE labeled ADS, macrophages were labeled with Wheat Germ Agglutinin Alexa Fluor 633 Conjugated. Labeled macrophages were then incubated with labeled ADS, the microscopy chamber plate was placed in the integrated chamber $\left(37{ }^{\circ} \mathrm{C}, 5 \% \mathrm{CO}_{2}\right)$ of LSM 780 Carl Zeiss and a mid-point cell thickness view images and z-stack images were obtained after $60 \mathrm{~min}$. Images were analyzed using ZEN 2012 lite software (ZEISS).

\subsection{Immunization procedures}

Female BALB/c mice, 8-10 weeks old, were purchased from Charles River (Barcelona, Spain) and kept under specificpathogen-free conditions at the Animal Facility of the Instituto de Ciências Biomédicas Abel Salazar, Porto, Portugal. All procedures involving mice were performed according to the European Convention for the Protection of Vertebrate Animals used for Experimental and other Scientific Purposes (ETS 123), the 86/609/EEC directive and Portuguese rules (DL 129/92). Twenty $\mathrm{BALB} / \mathrm{c}$ mice per group, were injected subcutaneously three times with a 2-week intervening period, with $200 \mu$ l of one of the following preparations: CWSP alone $(50 \mu \mathrm{g} / \mathrm{ml})$; DODAB:MO EL $(888 \mu \mathrm{g} /$ $\mathrm{ml})$, ADS1 (50:888 $\mu \mathrm{g} / \mathrm{ml}$; CWSP:Lipid) or ADS2 $(50: 133 \mu \mathrm{g} / \mathrm{ml}$; CWSP:Lipid). Additionally, a group of six mice was injected with HEPES-Buffer (vehicle), following the same immunization procedure. The schematic representation of the immunization protocol is shown in Fig. S2. Blood samples were collected in the submandibular vein on day 35 of the immunization protocol to obtain serum samples to confirm immunization efficiency.

\subsection{C. albicans hematogenously disseminated infections}

BALB/c mice were infected intravenously (i.v.) with $1 \times 10^{5} \mathrm{C}$. albicans yeast-form cells, according to the schedule presented in Fig. S2. C. albicans inoculum for infection was grown in a shaking incubator for $14 \mathrm{~h}$ at $30{ }^{\circ} \mathrm{C}$ in Winge medium ( $0.2 \%$ glucose, $0.3 \%$ 
yeast extract). Yeast cells were harvested, washed twice with sterile, apyrogenic phosphate-buffered saline (PBS), counted in a hemocytometer, and resuspended at the appropriate concentrations. Inocula were always confirmed by colony forming units (CFU) counts on YPD agar plates at $37{ }^{\circ} \mathrm{C}$ for up to $48 \mathrm{~h}$. In order to assess survival, eight mice of each of the four immunized groups, and the mouse group treated with the vehicle alone, were infected, weighted and monitored twice daily to evaluate the progress of hematological disseminated candidiasis. Mice attaining established human end points were humanely sacrificed using isoflurane anesthesia followed by cervical dislocation. Their deaths were recorded as occurring on the following day. To determine immunological parameters, eight mice of each immunized group were also infected with $1 \times 10^{5} \mathrm{C}$. albicans cells and sacrificed three and seven days after infection to collect blood and spleens.

\subsection{Intracytoplasmic cytokine quantification}

At days 49 (before infection), 52 and 56 (three and seven days post-infection, respectively) four immunized mice per group were sacrificed and the spleens were aseptically removed, homogenized in Hanks' balanced salt solution (Sigma) and red blood cells lysed with $0.15 \mathrm{M}$ ammonium chloride. The remaining cells were counted and plated in round-bottom 96-well plates (Nunc, $1 \times 10^{6}$ cells) in RPMI-1640 compete medium [RPMI-1640 (Sigma) supplemented with $10 \%$ FBS, HEPES (10 mM), penicillin (200 IU/ $\mathrm{ml}$ ), streptomycin $(200 \mathrm{~g} / \mathrm{ml})$ (all from Sigma) and 2mercaptoethanol $(0.1 \mathrm{mM})$ (Merk)]. Cells were incubated in a humidified atmosphere with $5 \% \mathrm{CO}_{2}$ at $37^{\circ}$ for $5 \mathrm{~h}$ under stimulation with $20 \mathrm{ng} / \mathrm{ml}$ PMA (Sigma), $200 \mathrm{ng} / \mathrm{ml}$ ionomycin (Merk) and $10 \mathrm{ng} / \mathrm{ml}$ brefeldin A (Epicentre Biotechologies, Madison, WI, USA). Then, cells were recovered and non-specific antibody binding was prevented by the pre-incubation with anti-Fc $\gamma \mathrm{R}$ mAb followed by incubation with anti-CD4 peridinin-chlorophyll proteincychrome 5.5 (PerCP-Cy5.5)-conjugated (clone RM4-5). Following extracellular CD4 staining cells were washed, fixed in $2 \%$ formaldehyde, washed again and permeabilized with $0.05 \%$ saponin (Sigma) in PBS solution. Intracytoplasmic staining was carried out with anti-interferon- $\gamma$ (IFN- $\gamma$ ) FITC-conjugated (clone XMG1.2) (Biolegend) and anti-IL-10 PE-conjugated (clone JES5-16E3) (BD Biosciences) or with anti-IL-4 PE-conjugated (clone BVD4-1D11) (BD Biosciences) and anti-IL-17A FITC conjugated (clone TC1118H10.1) (Biolegend). Antibody-labeled cells were analyzed in an EPICS XL flow cytometer using the EXPO32ADC software (Beckman Coulter). At least 150000 events were acquired per sample. The collected data files were analyzed using FLOWJO X 10.0.7r2 software.

\subsection{In vitro antigen-recall stimulation assay and cytokine quantification}

To assess cytokine production by CWSP-stimulated spleen cells, $5 \mathrm{ml}$ aliquots of cell suspensions prepared as described above for intra-cytoplasmic staining, were layered onto $2.5 \mathrm{ml}$ of a polysucrose-sodium ditrizoate solution (Histopaque $1083^{\circledR}$, Sigma) and centrifuged at $800 \mathrm{~g}$ for $20 \mathrm{~min}$ at room temperature. Mononuclear cells collected from the medium-Histopaque interface were collected, washed, suspended in RPMI-1640 complete medium, plated $\left(5 \times 10^{5} /\right.$ well) in round-bottom 96 -well plates, and stimulated with CWSP (final concentration of $20 \mu \mathrm{g} / \mathrm{ml}$ ) for 3 days at $37^{\circ}$ and $5 \% \mathrm{CO}_{2}$. The concentrations of IFN- $\gamma$, IL- 4 and IL- $17 \mathrm{~A}$ in cell culture supernatants were quantified with the respective Mouse ELISA Ready-Set-Go kit (eBioscience, San Diego, CA) while IL-10 was quantified using the Mouse IL-10 DuoSet ELISA development system (R\&D Systems, Minneapolis, MN) according to the manufacturer's instructions.

\subsection{Quantification of CWSP-specific antibodies}

Specific anti-CWSP immunoglobulins in the collected serum were quantified by ELISA according to Ferreirinha et al. [39]. Briefly, polystyrene microtitre plates (Nunc, Roskilde, Denmark) were coated with $5 \mu \mathrm{g} / \mathrm{ml}$ CWSP and incubated overnight at $4{ }^{\circ} \mathrm{C}$. Wells were then saturated for $1 \mathrm{~h}$ at room temperature with $1 \%$ BSA in Tris-saline Tween 20 (TST) (w/v) and serial dilutions of the serum samples were plated and incubated for $2 \mathrm{~h}$ at room temperature. After washing, alkaline phosphatase-coupled monoclonal goat anti-mouse IgG1 and IgG2a (Southern Biotechnology Associates, Birmingham, $\mathrm{AL}$ ) were added and incubated for $1 \mathrm{~h}$ at room temperature. After washing, the specifically bound antibodies were detected by adding the p-nitrophenyl phosphate (Sigma) substrate solution and on development the reaction was stopped by the addition of $0.1 \mathrm{M}$ EDTA, $\mathrm{pH} 8$ solution. The absorbance was measured at $405 \mathrm{~nm}$, subtracting for each well the value of the absorbance at $570 \mathrm{~nm}$. The antibody titers were expressed as the reciprocal of the highest dilution with an absorbance 2 fold higher than the value of the control (no serum added).

\subsection{Phagocytosis of opsonized C. albicans cells}

Phagocytosis was assessed by flow cytometry following a previously described method [40]. Briefly, fixed C. albicans cells were labeled with Sytox Green and incubated in Dulbecco's modified Eagle medium (DMEM) during $30 \mathrm{~min}$ at $37^{\circ} \mathrm{C}$ with $20 \%$ mouse serum collected from mice immunized thrice with CWSP, ADS1, ADS2 or EL. Serum from four independent mice was used, each one in triplicate. Then, cells were washed twice with PBS and resuspended in DMEM without serum. RAW 264.7 macrophages were incubated with labeled yeast suspensions at a multiplicity of infection (MOI) of 1 macrophage per 5 yeast cells, for $30 \mathrm{~min}$, at $37{ }^{\circ} \mathrm{C}$ and $5 \% \mathrm{CO}_{2}$. After incubation, plates were kept on ice to stop phagocytosis, and wells rinsed twice with PBS to remove unbound yeasts. Macrophages and associated yeasts were then incubated with PI at a final concentration of $6 \mu \mathrm{g} / \mathrm{ml}$, for $5 \mathrm{~min}$ at RT. The percentage of macrophages with internalized cells (Sytox ${ }^{+}$ $\mathrm{PI}^{-}$and Sytox ${ }^{+} \mathrm{PI}^{+}$), as well as the percentage of macrophages with adherent cells (Sytox ${ }^{-} \mathrm{PI}^{+}$), was determined as previously described [40]. Phagocytosis was confirmed by confocal microscopy (Leica SP2 AOBS SE) and images were analyzed using Fiji-Image software 2.00 (NIH-USA).

\subsection{Statistical analyses}

Data were analyzed using analysis of variance (ANOVA) followed by Bonferroni post-test to compare the mean values of the different groups, using GraphPad Prism 5 software (GraphPad Software, Inc., La Jolla, CA, USA). Unless otherwise stated, results shown are from at least three independent experiments with three replicates. Differences were considered significant when the $P$ value was lower than 0.05 .

\section{Results}

\subsection{Characterization of ADS, quantification of protein retention and delivery}

ADS used here were prepared using preformed DODAB:MO liposomes loaded with CWSP $(50 \mu \mathrm{g} / \mathrm{ml})$ as previously described [26]. ADS1 presented a size around $223 \pm 37 \mathrm{~nm}$ with a polydispersity index (PDI) of $0.19 \pm 0.015$, while ADS2 had a similar size, $255 \pm 46 \mathrm{~nm}$, but were more polydisperse, $0.25 \pm 0.017$ (Table 1). These ADS were negatively charged, with ADS1 presenting a 
$\zeta$-potential value of $-18.3 \pm 1.5 \mathrm{mV}$ and ADS2 a $\zeta$-potential value of $-21.8 \pm 1.5 \mathrm{mV}$, while DODAB:MO EL exhibited a $\zeta$-potential value of $54.6 \pm 3.2 \mathrm{mV}$, showing that antigenic proteins (CWSP) are surface adsorbed to liposomes. Owing to the complexity of Candida cell wall antigens and their surface localization, we thus focused on the stability over time of the proteins associated with the liposomes when stored at $4{ }^{\circ} \mathrm{C}$. Immediately after formulation assembling (time 0 ), ADS1 presented $91 \pm 12 \%$ of the proteins adsorbed while ADS2 showed only $25 \pm 12 \%$ (Fig. 1). Although by $48 \mathrm{~h}$ approximately $12.6 \%$ of CWSP were released from the surface of ADS1 liposomes and 17.1\% from the surface of ADS2, no significant changes were observed over $72 \mathrm{~h}$ after preparation. Thus, in this study, both ADS1 and ADS2 were used within $48 \mathrm{~h}$ after preparation to ensure the\% of CWSP absorbed. In this way, the effective concentration calculated taking into consideration the $50 \mu \mathrm{g} / \mathrm{ml}$ of total protein initially added ranged from $45.5 \pm 6-39.2 \pm 3 \mu \mathrm{g} /$ $\mathrm{ml}(91 \pm 12-78.4 \pm 5$ of CWSP absorption) for ADS1 and from $12.5 \pm 6-10.3 \pm 1 \mu \mathrm{g} / \mathrm{ml}(25 \pm 12-20.7 \pm 3 \%$ of CWSP absorption $)$ for ADS2. These results highlighted the fact that the interactions between DODAB:MO liposomes and CWSP proteins are strong and protein adsorption on to ADS1 or ADS2 is stable, at least over a range of $72 \mathrm{~h}$ after liposomes preparation and storage at $4{ }^{\circ} \mathrm{C}$.

In a previous study we have shown that ADS1 and ADS2 were non-toxic to J774A.1 macrophages and were avidly internalized by these cells [26]. In this study we confirmed by confocal microscopy that after $60 \mathrm{~min}$ of incubation ADS1 also effectively delivered CWSP into RAW 264.7 macrophages (Fig. 2). The results obtained with these different cell lines, indicate that these ADS are able to efficiently deliver antigens into macrophages that may trigger $\mathrm{T}$ and $\mathrm{B}$ cells in vivo.

\subsection{Immunostimulatory effect of ADS on dendritic cells}

The activation of antigen presenting cells (APC), such as dendritic cells, is one of the fundamental steps in inducing an effective in vivo immune response [14]. Therefore, we evaluated the ability of the formulations to activate BMDC in vitro by measuring surface expression of $\mathrm{T}$ cell co-stimulatory (CD80 and CD86) and MHC class II molecules, and by quantifying the production of proinflammatory cytokines TNF- $\alpha$, IL-12 and IL-23 and antiinflammatory cytokine IL-10 in the culture supernatants.

Fig. 3a shows that upon $6 \mathrm{~h}$ stimulation with CWSP, ADS1 and ADS2, BMDC already presented a significantly higher expression

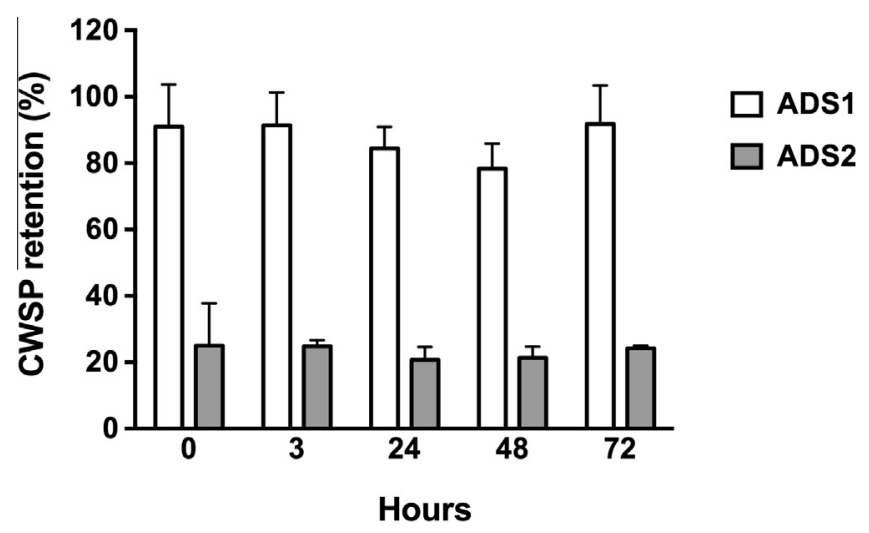

Fig. 1. Percentage of CWSP retention in ADS1 and ADS2 over time. ADS were prepared, stored at $4{ }^{\circ} \mathrm{C}$, and retention of CWSP antigen was monitored during $72 \mathrm{~h}$ after preparation. Each bar represents mean + SD of the percentage retention of initial antigen added $(50 \mu \mathrm{g} / \mathrm{ml}$ for both ADSs). Data shown are representative results of two independent experiments $(\mathrm{N}=3$ per experiment). of all the surface activation markers analyzed in comparison with unstimulated or EL stimulated cells. At this time point, no higher expression of the assessed BMDC cell surface markers was induced by any ADS, as compared to CWSP. Actually, ADS1-induced CD80 expression was lower than the one induced by CSWP. Contrastingly however, after $24 \mathrm{~h}$ incubation a markedly higher surface CD80, CD86 and MHC II expression was observed in the BMDC stimulated with ADS1 as compared to that induced by free CWSP (Fig. 3a). In contrast to ADS1, ADS2 did not promote an enhanced expression of those dendritic cell surface markers, comparatively to CWSP.

BMDC stimulated for $6 \mathrm{~h}$ with either CWSP or ADS2 produced similar levels of TNF- $\alpha$ and IL-12 as those stimulated with LPS, a strong activator of the innate immune system and a potent inducer of inflammation [41]. CWSP and ADS2 stimulated cells also produced significantly higher amounts of IL-23 and IL-10 when compared with stimulation by ADS1 or EL (Fig. 3b). After $24 \mathrm{~h}$ stimulation, the levels of TNF- $\alpha$, IL-12 as well as of IL-10 were maintained or enhanced in the cell culture supernatants of CWSP- or ADS2-stimulated BMDC, while those of IL-23 were lower, as compared to the respective ones detected at $6 \mathrm{~h}$. Contrastingly, stimulation with ADS1 led to intermediate levels of all cytokines, ranging between the ones detected when using CWSP or ADS2, and EL (Fig. 3b).

These results suggested that although both ADS1 and ADS2 activated BMDC, ADS2 and free CWSP appeared to be the most inflammatory stimuli. While ADS1 could stimulate BMDC, as assessed by significantly enhanced expression of surface co-stimulatory and MHC II proteins, the induced production of inflammatory cytokines as well as of IL-10 were significantly lower than the ones observed for ADS2 and CWSP.

\subsection{Production of antigen-specific antibodies in vivo}

Having determined that ADS1 and ADS2 stimulated BMDC, we next immunized BALB/c mice with these formulations. The serum titers of CWSP-specific IgG1 and IgG2a antibodies were determined in mice immunized with free CWSP, ADS1 and ADS2 or shamimmunized with EL as controls. As previously reported, mice immunized with free CWSP or ADS raised antigen-specific IgG antibodies that were significantly higher in the ADS1 immunized group, as compared to the other assessed groups (Fig. 4a). Mice immunized with ADS2 or free CWSP presented similar levels of anti-CWSP IgG1 and IgG2a antibodies. The efficacy of serum from immunized mice in enhancing the phagocytosis of $C$. albicans cells was then tested in vitro and analyzed by flow cytometry using a previous described method that enables the discrimination of yeast cells that are internalized from yeast cells that are only adhered to phagocytes (fig. 4c) [40]. As shown in Fig. 4b, C. albicans cells pre-treated with serum from mice immunized with ADS1 and ADS2 were significantly more internalized by macrophages than non-opsonized yeast cells or cells opsonized with serum from mice sham-immunized with EL or immunized with CWSP alone. This indicates that the increased percentage of $C$. albicans yeasts internalized by macrophages was due to CWSP-specific IgG yeast opsonization. Although serum from CWSP-immunized mice contained CWSP-specific IgG, no differences in the percentage of internalized yeast were observed for yeast cells treated with this serum in comparison with cells treated with serum from mice immunized with EL. This result might be a consequence of low CWSP-specific IgG titles detected in serum of mice immunized with free antigen. According to all these results, mice immunized with ADS presented a significant increase in serum CWSP-specific antibody titers before infection that markedly enhanced ex vivo phagocytosis of C. albicans yeast cells. 


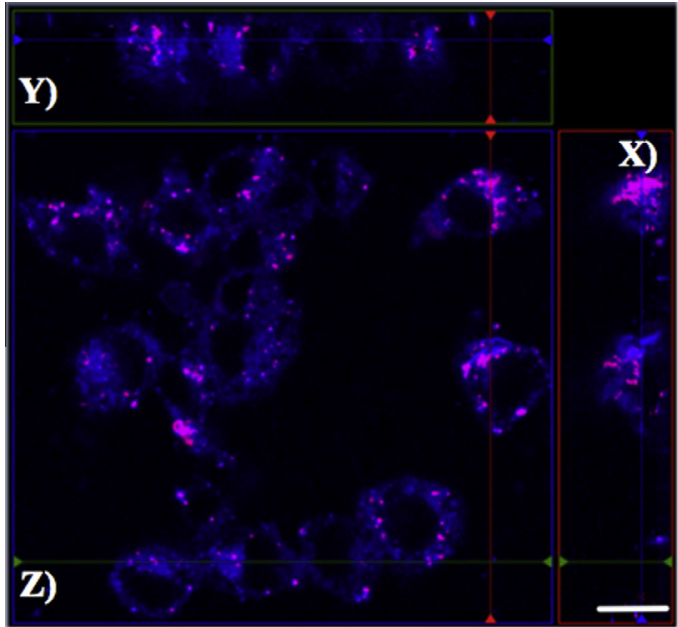

Empty liposomes

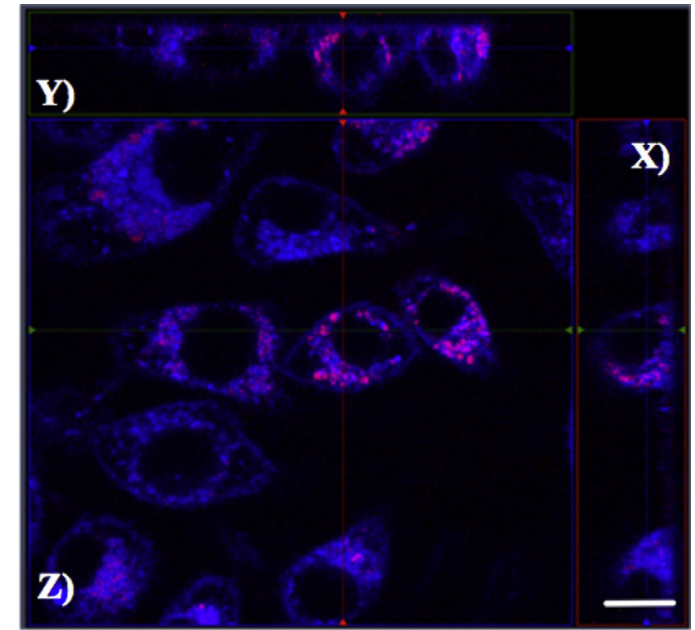

ADS1 LNPs

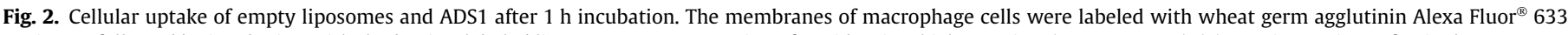

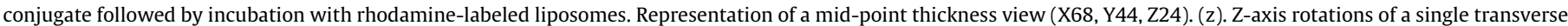
slice through two sections of the cell: view in the $\mathrm{x}-0-\mathrm{z}$ plane $(\mathrm{x})$ and view in the $\mathrm{y}-0-\mathrm{z}$ plane $(\mathrm{y})$. The scale bar represents 10 nm.

\subsection{ADS vaccination protects against hematogenously disseminated $C$. albicans infection}

In order to evaluate the protective effect of ADS1 and ADS2 immunization against systemic candidiasis, s.c. vaccinated and control mice were challenged at day 49 with a clinical $C$. albicans isolate obtained from a patient with systemic infection (strain 124A [35]). The immunization protocol is schematized in Fig. S2 (supplementary data). Mice were weighted and visually monitored for signs of disease over 50 days. Mice sham-immunized with EL were the first attaining established humane endpoints, by day 8 upon infection and were closely followed by mice of the CWSP and ADS2 immunized groups. In the ADS1 immunized group, only by day 15 the first mouse death was recorded (Fig. 5). Moreover, only the ADS1 immunized group presented a significantly extended survival as compared to any of the other experimental groups. By the end of the experimental period, $62.5 \%$ of the mice immunized with ADS1 survived infection as compared to $12.5 \%$ in the EL treated group and $100 \%$ mortality in the CWSP and ADS2 immunized groups. These results show that ADS1, but not the other immunogenic preparations, conferred protection against C. albicans challenge. Moreover, as the C. albicans strain used to isolate CWSP antigens was different from the one used to infect the immunized mice it may indicate that achieved protection could be strain-independent.

\subsection{Splenocytes stimulation and intracellular cytokine quantification}

Cell-mediated immunity is essential for the control of $C$. albicans and Th1- and Th17-type cytokines are critical for coordinating protective immunity against the fungus [42]. Thus, to determine whether the immunization with either ADS could induce a particular type of $T$ cell polarization, the expression of IFN- $\gamma$, IL-4, IL-10 and IL-17 was assessed by flow cytometry in splenic CD4 ${ }^{+} \mathrm{T}$ cells collected from mice of the different assessed groups (Fig. 6). IFN$\gamma$ and IL-17 are main effectors in the protective immune response

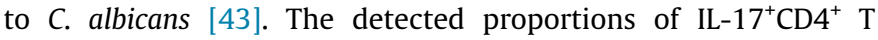
splenocytes were significantly and markedly higher in the ADS1immunized mice, as particularly evident in 3-day infected mice.
Contrastingly, the frequency of splenic $\mathrm{CD}^{+} \mathrm{T}$ cells producing IFN- $\gamma$ was not majorly altered among groups upon infection. Nevertheless, significantly lower frequency of IFN $-\gamma^{+} \mathrm{CD} 4^{+}$cells was detected in the ADS1-immunized mice as compared with the frequency found for CWSP-immunized mice. Immunization with ADS1 or ADS2 also increased the proportions of splenic IL- $4^{+}$and IL- $10^{+} \mathrm{CD}^{+} \mathrm{T}$ cells, as compared with mice immunized with EL or CWSP (Fig. 6a). The increase in $\mathrm{IL}^{+} \mathrm{CD}^{+} \mathrm{T}$ cell proportions was higher only in ADS1 immunized mice, as compared to CWSP immunized counterparts. These results indicate that immunization with ADS, and more markedly with ADS1, induced a balanced immune response encompassing pro- and anti-inflammatory cytokine production.

Cytokine production was also assessed by ELISA in culture supernatants of CWSP-stimulated splenocytes obtained from the different used mouse groups, Before infection, a mild production of pro-inflammatory cytokines IFN- $\gamma$ and IL-17 was detected in CWSP-stimulated splenocytes of mice immunized with ADS1. That was nevertheless higher than that detected in splenocytes of mice immunized with CWSP or EL in which no or very little production of these cytokines was detected (Fig. 7). At this time point, a mild production of IFN- $\gamma$ was also detected in similarly stimulated splenocytes of ADS2 immunized mice. In the cultures of splenocytes collected at day 53 (3 days after C. albicans i.v. infection), the levels of IFN- $\gamma$ were found significantly increased in culture supernatants of all assessed splenocyte groups. However, production of IL-17 and of IL- 4 was markedly higher in the groups corresponding to ADS1 immunized mice, detected in cultures of splenocytes collected at days 52 and 56 ( 3 and 7 upon infection, respectively). Splenocytes of the ADS2 immunized group also produced these cytokines upon stimulation, although at lower levels than those detected in the ADS1 group. No IL-17 production was detected in the remaining splenocyte culture from other mouse groups. IL-4 production by splenocytes of the CWSP immunized mice was detected, although at very low levels (Fig. 7). Interestingly in the cultures of splenocytes collected from both ADS immunized groups 3 and 7 days upon infection, significantly higher levels of IL-10 were detected upon the antigenic stimulation than in the other two groups (Fig. 7). 
a
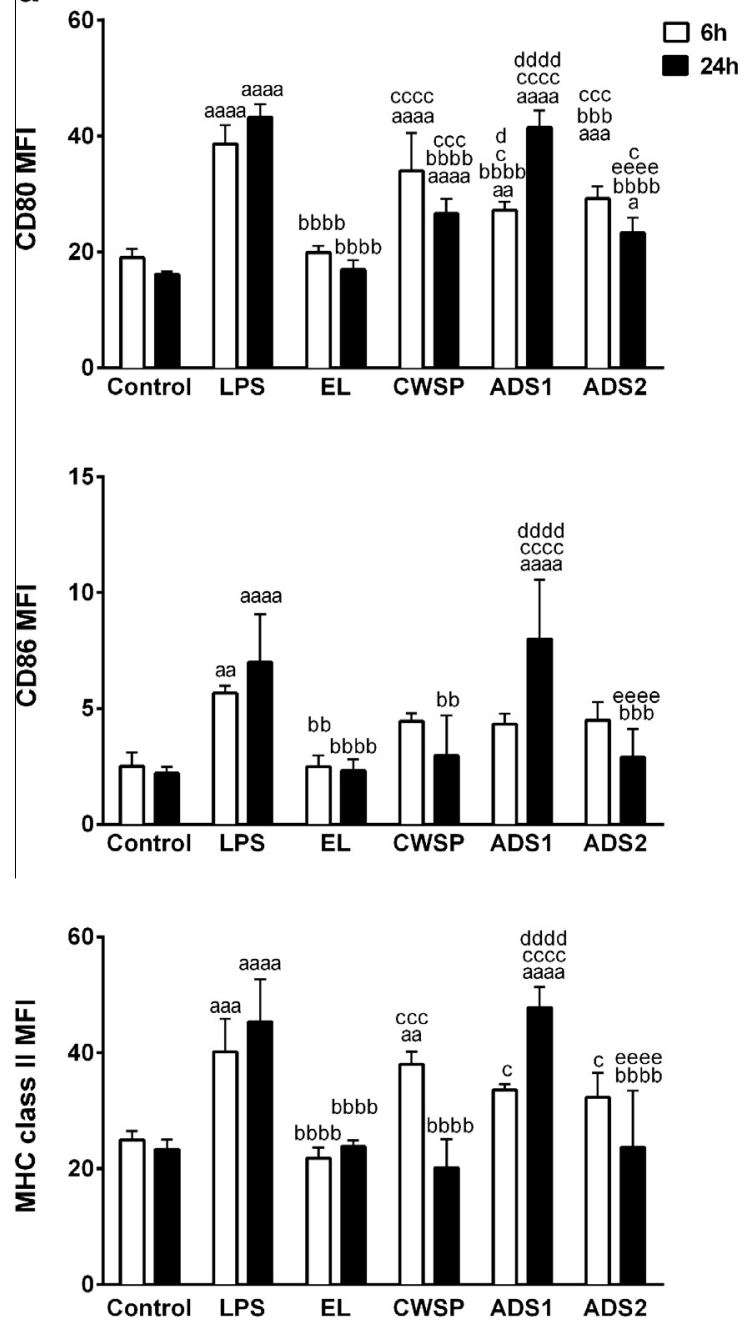

b
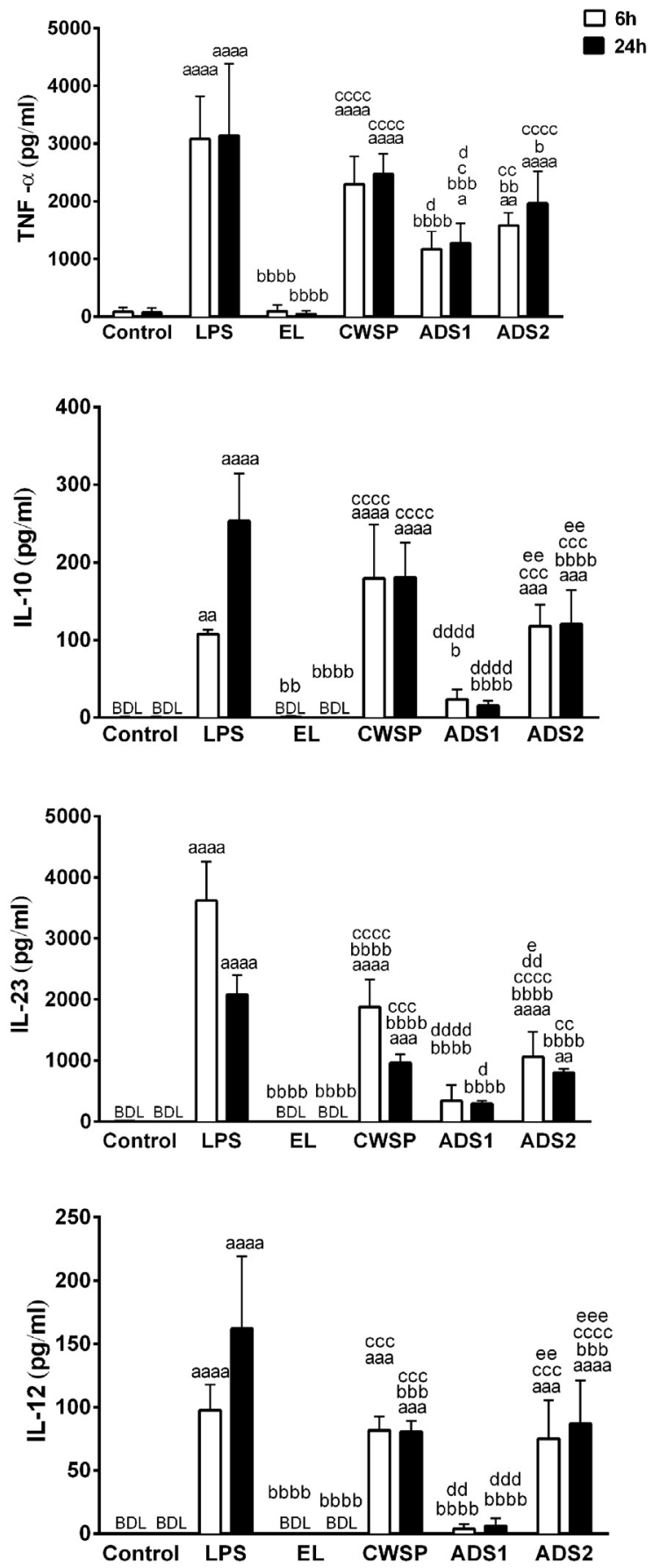

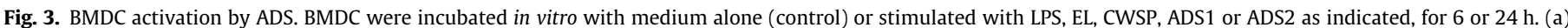

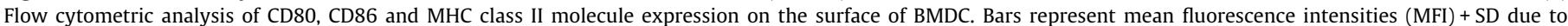

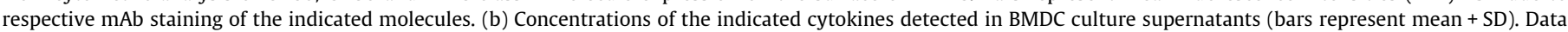

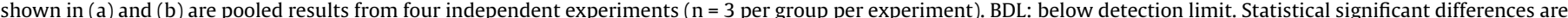

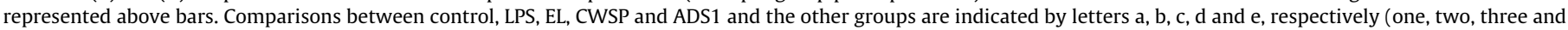
four letters correspond to $\mathrm{P}<0.05, \mathrm{P}<0.01, \mathrm{P}<0.001$ and $\mathrm{P}<0.0001$, respectively).

\section{Discussion}

The surge of Candida species infections coupled to higher resistance rates to antifungal drugs resulted in a tremendous increase in the prevalence of systemic candidiasis in hospitalized patients over the past two decades [30-33]. Hence, the development of novel immune-based approaches that could prevent Candida infections is of paramount interest.

In a previous study, we have shown that DODAB:MO liposomes loaded with $C$. albicans CWSP improved the immunogenicity of these antigens which suggested that these liposomes could be promising delivery systems for use in vaccination against 


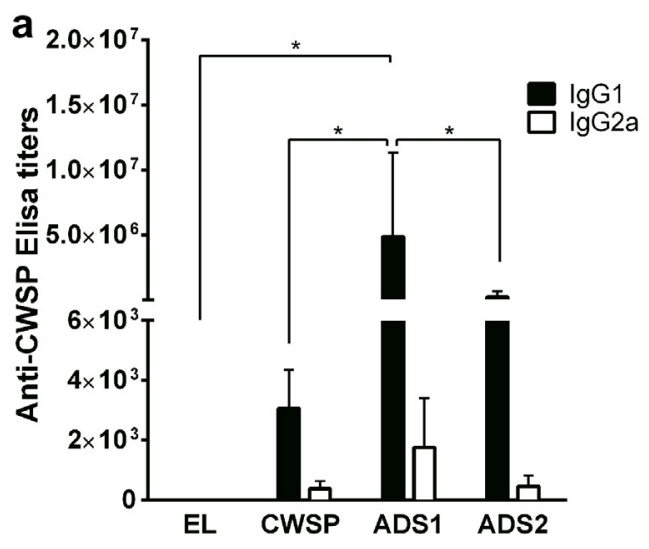

b

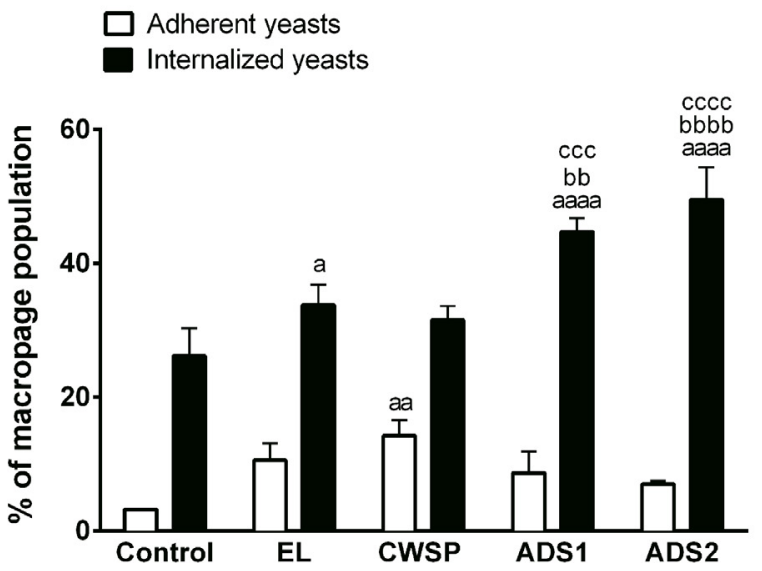

C

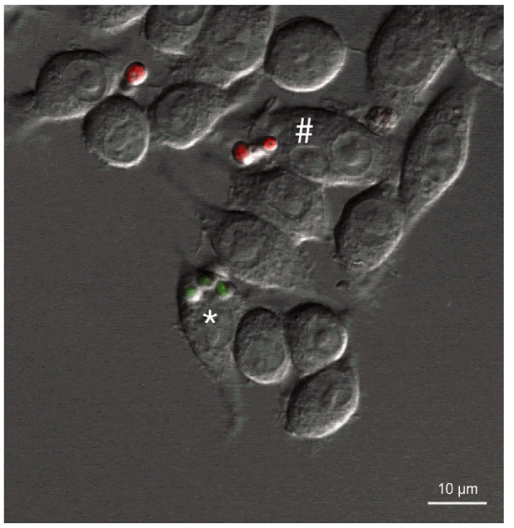

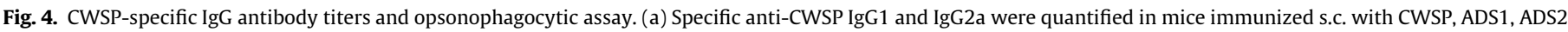

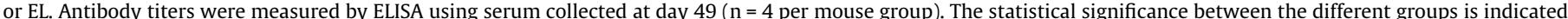

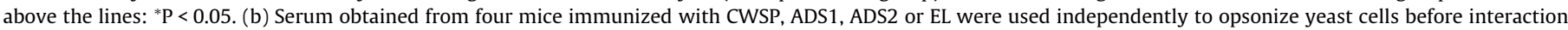

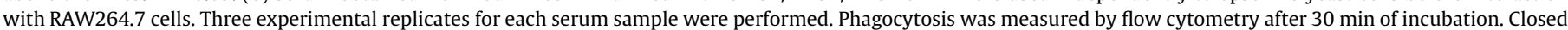

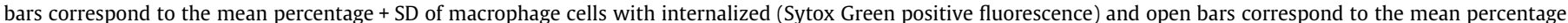

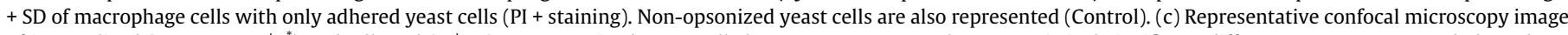

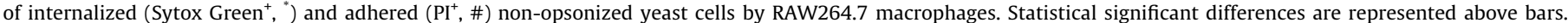

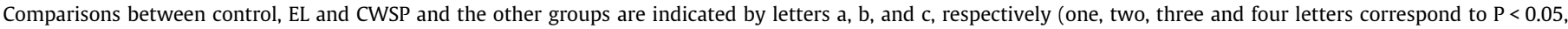
$\mathrm{P}<0.01, \mathrm{P}<0.001$ and $\mathrm{P}<0.0001$, respectively).

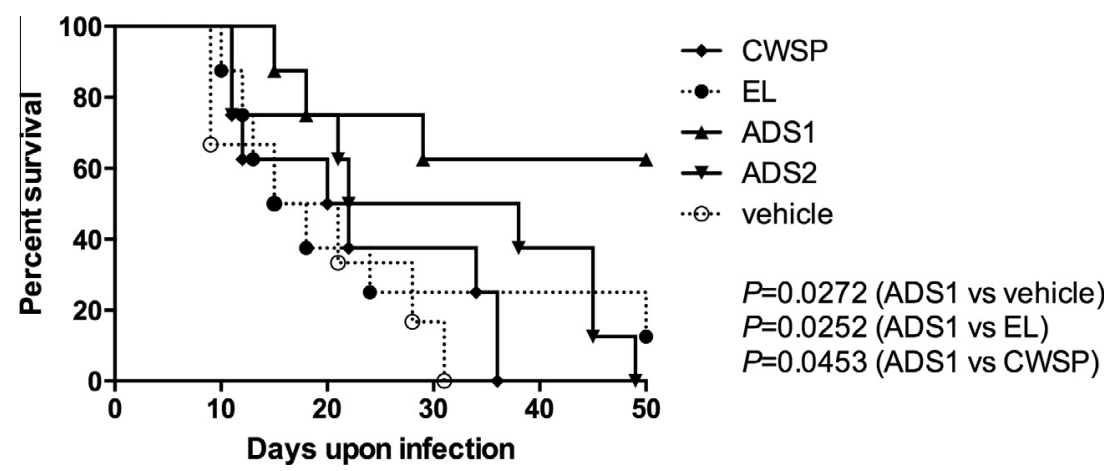

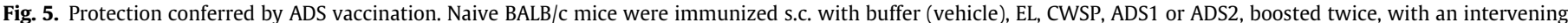

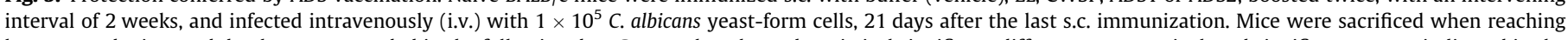

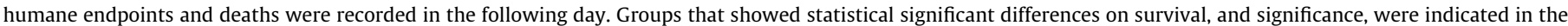
figure ( $\mathrm{n}=6$ and $\mathrm{n}=8$ in control and immunized groups, respectively).

C. albicans [26]. The proteins present in the fungal cell wall are good candidates for vaccine development due to their exposed location [44]. In addition, the combination of antigens that are related to key $C$. albicans virulence attributes or biological functions may induce additive or synergistic immune responses and therefore reduce the probability of fungal immune evasion [45].
The ADS were prepared as two vaccine formulations, ADS1 and ADS2, differing only in the total lipid concentration used for CWSP adsorption. ADS1 is composed by approximately 7 times more total lipid than ADS2 and, as a consequence, it retains $91 \pm 12 \%$ of the protein added, while ADS2 only retains $25 \pm 12 \%$, as previously reported [26]. Its characterization confirmed the ADS mean sizes to 
a
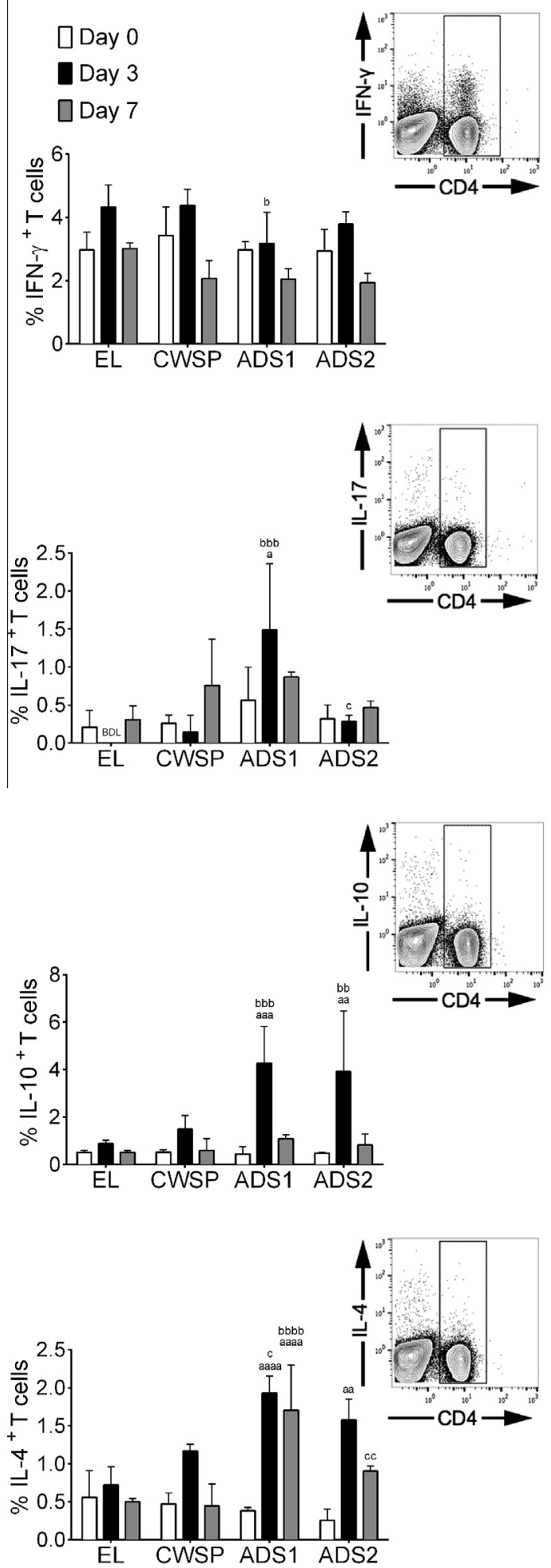
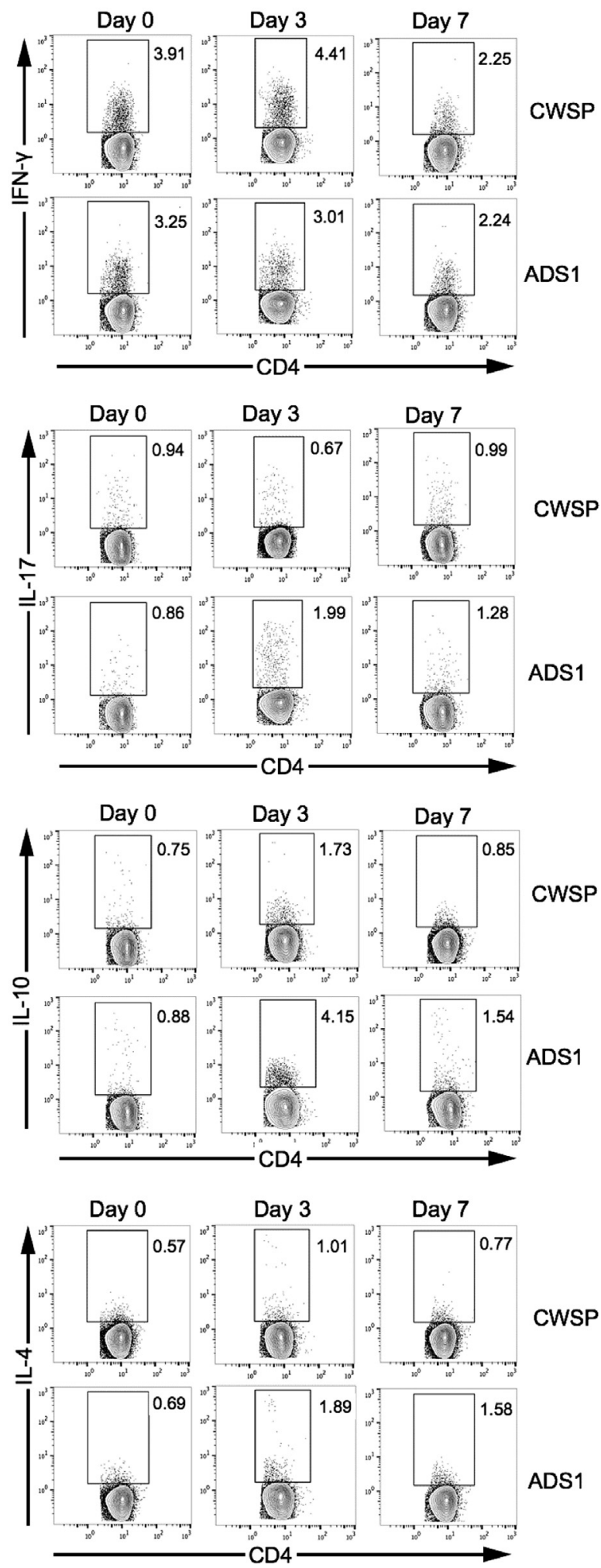

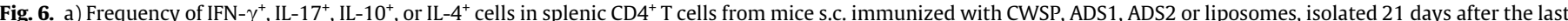

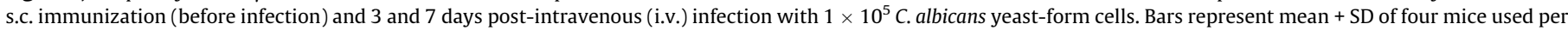

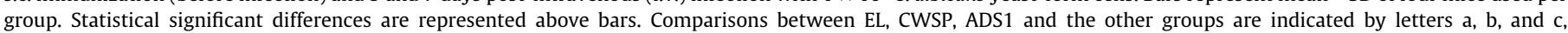

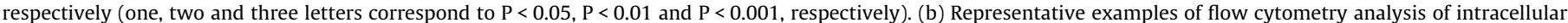

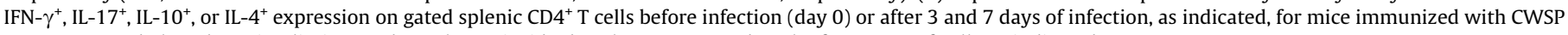
or ADS1. BDL: below detection limit. Numbers shown inside dot plots correspond to the frequency of cells as indicated. 

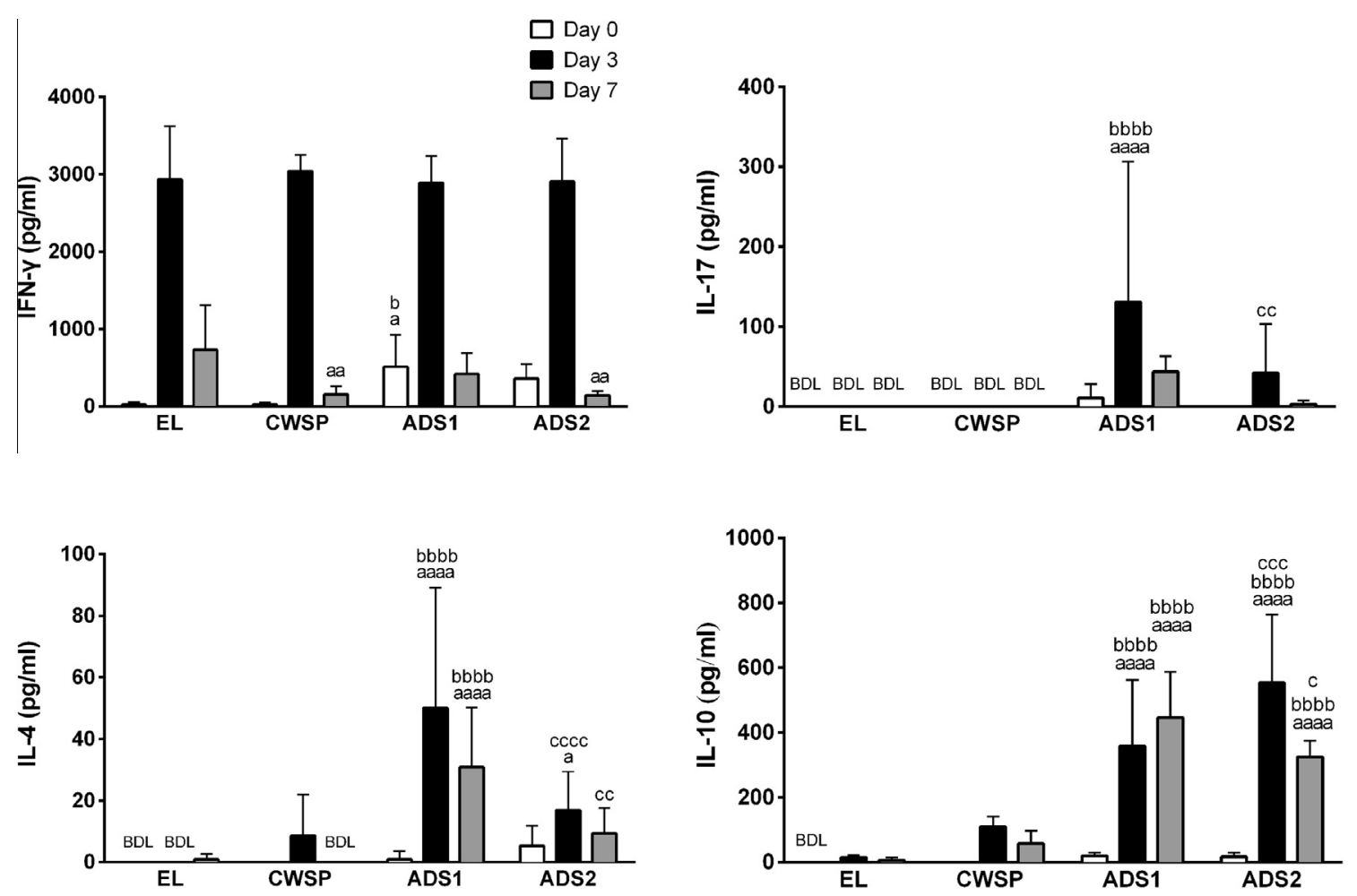

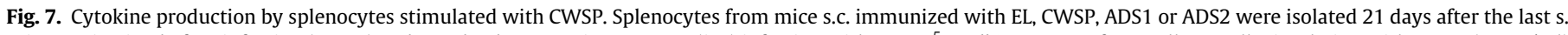

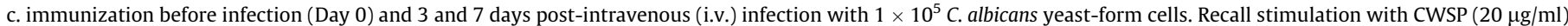

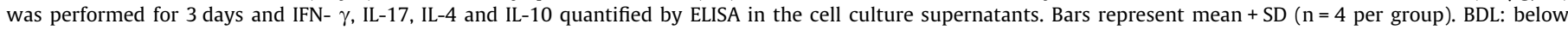

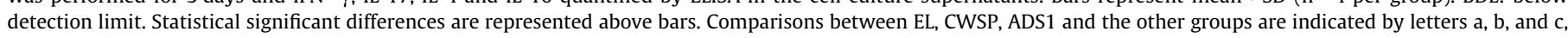
respectively (one, two, three and four letters correspond to $\mathrm{P}<0.05, \mathrm{P}<0.01, \mathrm{P}<0.001$ and $\mathrm{P}<0.0001$, respectively).

be approximately 223 and $255 \mathrm{~nm}$ for ADS1 and ADS2 respectively, and that the antigenic proteins are adsorbed to the cationic liposomes, as shown by $\zeta$-potential values. Furthermore, the electrostatic interactions between the cationic liposomes and the anionic proteins are strong enough to retain the antigens at the ADS surface for at least 3 days after preparation. Importantly, the quantity of antigens loaded in the ADS is dependent of the total lipid concentration, but the stability of the core proteins at their surface is not.

DC are important antigen presenting cells (APC) as they are very effective in antigen capturing, processing and subsequent presentation to antigen-specific T cells $[41,46]$. DC maturation in vitro is characterized by up-regulation of MHC II and the co-stimulatory molecules CD80 and CD86 [47]. Un-stimulated DC express moderate levels of CD80, CD86 and MHC-II molecules on their surface. Here we show that stimulation with ADS1, but not ADS2, significantly elevated the expression of these three markers, in comparison to cells exposed to the same concentration of free CWSP. Importantly, the activation promoted by CWSP was more transient than the one obtained with ADS1. This may indicate that delivery of CWSP using the DODAB:MO liposomes resulted in more sustained release of the target antigen or that the particulate nature of the ADS1 improved the antigen uptake by DC. Accordingly, the ability of cationic lipids to improve antigen immunogenicity was also observed in previous reports [48-50]. In contrast to ADS1, ADS2 was not effective in promoting significant DC activation. The lower lipid concentration used in this system, which results in just about $20 \%$ of CSWP entrapment, may explain the observed lack of adjuvant effect and the response similar to the one of free CWSP.

IL-12 and IL-23 are members of a family of heterodimeric proinflammatory cytokines that can respectively promote Th1 and
Th17 responses [51]. IL-12 induces IFN- $\gamma$ expression in $\mathrm{CD}^{+} \mathrm{T}$ cells [52], and IL-23 maintains Th17 effector function [53]. In contrast, IL-10 might be required to limit host damage under circumstances of strong inflammation [54]. The cytokine profile obtained by stimulating DC with ADS2 and free CWSP, encompassing TNF- $\alpha$, IL-12 and IL-23 production, revealed a response similar to that elicited by LPS, which could be considered as pro-inflammatory. On the contrary, ADS1 seemed to be less inflammatory since these cytokines were present but in significantly reduced levels. In accordance with a previous report [41], incubation of DC with EL didn't lead to production of significant levels of all cytokines, which indicates that the marked pro-inflammatory response induced by CWSP and ADS2 stimuli was likely due to the presence of high concentrations of free proteins in the incubation solution. In accordance, $C$. albicans cell wall proteins have been previously considered proinflammatory [55,56].

Although ADS2 and CWSP induced a more marked proinflammatory response by BMDC, ADS1 was the only system conferring significant protection to $C$. albicans challenge. Cytokine production analysis showed that mice immunized with ADS1 presented the highest frequency of splenic IL-17-producing CD4 $4^{+}$ T cells. The bias towards IL-17 production in the ADS1 immunized mice was confirmed by in vitro recall stimulation of splenocytes with CWSP antigen. Contrastingly, no major differences among groups were noticed in what concerned production of IFN- $\gamma$. IL17 was shown to be a particularly important cytokine in mediating protection against $C$. albicans infections in both humans and mice [57]. Therefore, the detected higher production of IL-17 may have contributed for the protective effect conferred by ADS1, as shown by the extended survival of the mice immunized with this formulation. IFN- $\gamma$ is also a recognized cytokine in mediating host protection against $C$. albicans [43]. However, as its production did 
not markedly vary upon the fungal challenge in the different assessed mouse groups it is unlikely that it may determine the higher protective effect conferred by ADS1. ADS1 was the antigen-delivery system inducing the highest production of CWSP-specific antibodies, which led to, along with ADS2, to highest yeast opsonophagocytosis by macrophage cells. Immunization with ADS1 resulted in higher protection, indicating that protection could also be due to opsonizing antibodies raised by immunization before infection. The host protective role of $C$. albicans cell-wall specific antibodies has been previously documented [58] and might be expected to also contribute for the immunoprotective effect of the assessed ADS.

Although Th17 and Th1 cells, respective producers of IL-17 and IFN- $\gamma$, have been shown to be important in the development of protective host responses against $C$. albicans infection [42,59], it is the balance between pro- and anti-inflammatory signaling that defines a successful fungal control [60,61]. In C. albicans infected hosts Th1 cells secrete IFN- $\gamma$ favouring phagocyte cells activity [43] while Th17 cells enhance neutrophil recruitment through secretion of IL-17 [59,62]. Despite Th17 cells through IL-17 production undoubtedly contribute to fungal elimination in infected hosts, the pro-inflammatory effect of these cells may be deleterious to the host [63]. Here, at day 3 post-infection, the proinflammatory response was marked in all immunized mice. However, and importantly, also at this time point, the ADS immunized mice showed the highest production of anti-inflammatory cytokine IL-10. As previously remarked, a vaccine that could elicit by itself an inflammatory reaction might end damaging the host when the infectious agent is encountered. In such case, IL-10 production may act as a homeostatic response to keep inflammation under control [54,64]. Indeed, a previous reported experimental vaccine that elicited a mixed response involving pro-inflammatory and anti-inflammatory cytokines could provide host protection in the absence of significant tissue pathology [65]. In mice immunized with ADS1, the production of IFN- $\gamma$ and IL-17, Th1- and Th17type cytokines, respectively, as well as IL-4 and IL-10, Th2-type and anti-inflammatory cytokines, respectively, supports the idea that DODAB:MO liposomes contribute to a balanced immune response against $C$. albicans infection, that ultimately culminated in host extended survival, when compared with free CWSP immunization. These results highlight once more the adjuvant potential of these DODAB:MO liposomes, suggesting that a decrease in lipid concentration could be fatal once ADS2 failed in inducing protection against systemic candidiasis.

Currently, scientific interest has grown towards the development of nanoparticles for use as adjuvants and delivery of antigens for vaccine development [66-70]. Other studies, using DODAB liposomes with monophosphoryl lipid A (MPLA) or with trehalose 6,6'dibehenate (TDB) as adjuvants, also resulted in a protective immune response towards Chlamydia infection [71]. Similarly, in another study, the combination of DODAB with a major antigen of Paracoccidioides brasiliensis resulted in the lowest numbers of viable yeast cells in mice infected with this fungus in comparison with the use of other adjuvants such as aluminum hydroxide, Freund's Complete Adjuvant (CFA) or flagellin [72]. Other authors have described enhanced protection provided by liposomes with entrapped Candida antigens. In one of the studies the authors used a double immunization strategy with priming antigen dose of $50 \mu \mathrm{g}$ and boosted with $25 \mu \mathrm{g}$ [61]. Chauhan and co-authors using escheriosomes with entrapped Candida antigen were able to protect mice against $C$. albicans infection upon two immunizing administrations using $100 \mu \mathrm{g}$ of antigen per immunization [73]. Of note, in the present study only a total $30 \mu \mathrm{g}$ of antigen were used divided in three immunizing administrations, which is a small amount in comparison to that used in other studies, supporting the high adjuvant potential of DODAB:MO liposomes. This was the first time that this novel DODAB:MO liposomal nanoparticle associated with $C$. albicans CWSP was tested in a systemic $C$. albicans infection reaching $62.5 \%$ protection. This reveals a good potential for future vaccine design. Nevertheless, the major goal of any vaccine development is to achieve $100 \%$ protection. The administration route is a key issue in vaccination by affecting the type and strength of the elicited immune response [74]. Therefore the intradermal and intramuscular routes may be worth to explore in further studies as possible ways to achieve higher protection.

\section{Conclusion}

This study demonstrated that DODAB:MO-based ADS efficiently enhanced the stimulatory effect of CWSP and furthers the evidence suggesting that it is a promising new vaccine antigen delivery system. The in vivo results showed that by using DODAB:MO in the ADS1 formulation, an immunizing dose as low as $10 \mu \mathrm{g}$ of antigen administered three times elicited significant humoral and cellular immune responses in BALB/c mice, conferring significant protection against $C$. albicans systemic infection. Thus, the use of this novel ADS1 liposomal nanoparticle revealed good potential for future vaccine design.

\section{Disclosures}

The authors declare no conflict of interest.

\section{Acknowledgements}

This work was supported by the strategic programme UID/ BIA/04050/2013 (POCI-01-0145-FEDER-007569) funded by national funds through the FCT I.P. and by the ERDF through the COMPETE2020 - Programa Operacional Competitividade e Interna cionalização (POCI). Catarina Carneiro holds scholarship SFRH/ BD/69068/2010. We acknowledge NanoDelivery-I\&D em Bionanotecnologia, Lda for access to their equipment.

\section{Appendix A. Supplementary data}

Supplementary data associated with this article can be found, in the online version, at http://dx.doi.org/10.1016/j.actbio.2016.05. 001.

\section{References}

[1] S.A. Plotkin, Vaccines: past, present and future, Nat. Med. 11 (2005) S5-S11. [2] S. Banik, A.A. Mansour, R.V. Suresh, S. Wykoff-Clary, M. Malik, et al., Development of a multivalent subunit vaccine against tularemia using tobacco mosaic virus (TMV) based delivery system, PLoS ONE 10 (2015) e0130858.

[3] Y. Perrie, A.R. Mohammed, D.J. Kirby, S.E. McNeil, V.W. Bramwell, Vaccine adjuvant systems: enhancing the efficacy of sub-unit protein antigens, Int. J. Pharm. 364 (2008) 272-280.

[4] Y. Perrie, D. Kirby, V.W. Bramwell, A.R. Mohammed, Recent developments in particulate-based vaccines, Recent Pat. Drug Deliv. Formul. 1 (2007) 117-129.

[5] K.A. Ghaffar, A.K. Giddam, M. Zaman, M. Skwarczynski, I. Toth, Liposomes as nanovaccine delivery systems, Curr. Top. Med. Chem. (2014).

[6] A. Garcia, J.B. De Sanctis, An overview of adjuvant formulations and delivery systems, APMIS 122 (2014) 257-267.

[7] D. Christensen, K.S. Korsholm, P. Andersen, E.M. Agger, Cationic liposomes as vaccine adjuvants, Expert Rev. Vaccines 10 (2011) 513-521.

[8] M.J. Hussain, A. Wilkinson, V.W. Bramwell, D. Christensen, Y. Perrie, Th1 immune responses can be modulated by varying dimethyldioctadecylammonium and distearoyl-sn-glycero-3-phosphocholine content in liposomal adjuvants, J. Pharm. Pharmacol. 66 (2014) 358-366.

[9] D. Christensen, K.S. Korsholm, I. Rosenkrands, T. Lindenstrom, P. Andersen, et al., Cationic liposomes as vaccine adjuvants, Expert Rev. Vaccines 6 (2007) 785-796.

[10] E.M. Varypataki, K. van der Maaden, J. Bouwstra, F. Ossendorp, W. Jiskoot, Cationic liposomes loaded with a synthetic long peptide and poly(I:C): a 
defined adjuvanted vaccine for induction of antigen-specific T cell cytotoxicity, AAPS J. (2014)

[11] A.V. Yadav, M.S. Murthy, A.S. Shete, S. Sakhare, Stability aspects of liposomes, Indian J. Pharm. Educ. Res. 45 (2011) 402-413.

[12] R.A. Schwendener, Liposomes as vaccine delivery systems: a review of the recent advances, Ther. Adv. Vaccines 2 (2014) 159-182.

[13] E.M. Varypataki, A.L. Silva, C. Barnier-Quer, N. Collin, F. Ossendorp, et al., Synthetic long peptide-based vaccine formulations for induction of cell mediated immunity: a comparative study of cationic liposomes and PLGA nanoparticles, J. Control. Release (2016).

[14] P.C. Soema, G.J. Willems, W. Jiskoot, J.P. Amorij, G.F. Kersten, Predicting the influence of liposomal lipid composition on liposome size, zeta potential and liposome-induced dendritic cell maturation using a design of experiments approach, Eur. J. Pharm. Biopharm. 94 (2015) 427-435.

[15] A.C. Oliveira, T.F. Martens, K. Raemdonck, R.D. Adati, E. Feitosa, et al., Dioctadecyldimethylammonium:monoolein nanocarriers for efficient in vitro gene silencing, ACS Appl. Mater. Interfaces (2014).

[16] A.M. Carmona-Ribeiro, Biomimetic particles in drug and vaccine delivery, J. Liposome Res. 17 (2007) 165-172.

[17] N. Lincopan, N.M. Espindola, A.J. Vaz, M.H. da Costa, E. Faquim-Mauro, et al., Novel immunoadjuvants based on cationic lipid: preparation, characterization and activity in vivo, Vaccine 27 (2009) 5760-5771.

[18] N. Lincopan, M.R. Santana, E. Faquim-Mauro, M.H. da Costa, A.M. CarmonaRibeiro, Silica-based cationic bilayers as immunoadjuvants, BMC Biotechnol. 9 (2009) 5.

[19] K.S. Korsholm, E.M. Agger, C. Foged, D. Christensen, J. Dietrich, et al., The adjuvant mechanism of cationic dimethyldioctadecylammonium liposomes, Immunology 121 (2007) 216-226.

[20] J. Davidsen, I. Rosenkrands, D. Christensen, A. Vangala, D. Kirby, et al., Characterization of cationic liposomes based on dimethyldioctadecylammonium and synthetic cord factor from $M$. tuberculosis (trehalose 6,6'-dibehenate)-a novel adjuvant inducing both strong CMI and antibody responses, Biochim. Biophys. Acta 1718 (2005) 2231.

[21] A. Vangala, D. Kirby, I. Rosenkrands, E.M. Agger, P. Andersen, et al., A comparative study of cationic liposome and niosome-based adjuvant systems for protein subunit vaccines: characterisation, environmental scanning electron microscopy and immunisation studies in mice, J. Pharm. Pharmacol. 58 (2006) 787-799.

[22] J.P. Silva, I.M. Oliveira, A.C. Oliveira, M. Lucio, A.C. Gomes, et al., Structural dynamics and physicochemical properties of pDNA/DODAB:MO lipoplexes: effect of $\mathrm{pH}$ and anionic lipids in inverted non-lamellar phases versus lamellar phases, Biochim. Biophys. Acta 1838 (2014) 2555-2567.

[23] J.P. Silva, A.C. Oliveira, M.P. Casal, A.C. Gomes, P.J. Coutinho, et al. DODAB:monoolein-based lipoplexes as non-viral vectors for transfection of mammalian cells, Biochim. Biophys. Acta 1808 (2011) 2440-2449.

[24] I.M. Oliveira, J.P. Silva, E. Feitosa, E.F. Marques, E.M. Castanheira, et al., Aggregation behavior of aqueous dioctadecyldimethylammonium bromide/monoolein mixtures: a multitechnique investigation on the influence of composition and temperature, J. Colloid Interface Sci. 374 (2012) 206-217.

[25] A. Correia, U. Lermann, L. Teixeira, F. Cerca, S. Botelho, et al., Limited role of secreted aspartyl proteinases Sap1 to Sap6 in Candida albicans virulence and host immune response in murine hematogenously disseminated candidiasis, Infect. Immun. 78 (2010) 4839-4849.

[26] C. Carneiro, A. Correia, T. Collins, M. Vilanova, C. Pais, et al., DODAB:monoolein liposomes containing Candida albicans cell wall surface proteins: A novel adjuvant and delivery system, Eur. J. Pharm. Biopharm. 89 (2015) 190-200.

[27] B. Spellberg, Vaccines for invasive fungal infections, in: F1000 Med. Rep. 3 (2007) 13.

[28] M.A. Pfaller, D.J. Diekema, Epidemiology of invasive candidiasis: a persistent public health problem, Clin. Microbiol. Rev. 20 (2007) 133-163.

[29] G. Caggiano, C. Coretti, N. Bartolomeo, G. Lovero, O. De Giglio, et al., Candida bloodstream infections in Italy: changing epidemiology during 16 years of surveillance, Biomed. Res. Int. 2015 (2015) 256580.

[30] J.E. Edwards Jr., Fungal cell wall vaccines: an update, J. Med. Microbiol. 61 (2012) 895-903.

[31] A.S. Ibrahim, J.E. Edwards Jr., R. Bryant, B. Spellberg, Economic burden of mucormycosis in the United States: can a vaccine be cost-effective?, Med Mycol. 47 (2009) 592-600.

[32] G.D. Brown, D.W. Denning, S.M. Levitz, Tackling human fungal infections, Science 336 (2012) 647.

[33] C.S. Schmidt, C.J. White, A.S. Ibrahim, S.G. Filler, Y. Fu, et al., NDV-3, a recombinant alum-adjuvanted vaccine for Candida and Staphylococcus aureus, is safe and immunogenic in healthy adults, Vaccine 30 (2012) 75947600.

[34] F. De Bernardis, M. Amacker, S. Arancia, S. Sandini, C. Gremion, et al., A virosomal vaccine against candidal vaginitis: immunogenicity, efficacy and safety profile in animal models, Vaccine 30 (2012) 4490-4498.

[35] P. Sampaio, M. Santos, A. Correia, F.E. Amaral, J. Chavez-Galarza, et al., Virulence attenuation of Candida albicans genetic variants isolated from a patient with a recurrent bloodstream infection, PLoS ONE 5 (2010) e10155.

[36] A.D. Bangham, M.M. Standish, J.C. Watkins, Diffusion of univalent ions across the lamellae of swollen phospholipids, J. Mol. Biol. 13 (1965) 238-252.

[37] F. Cerca, A. Franca, B. Perez-Cabezas, V. Carvalhais, A. Ribeiro, et al., Dormant bacteria within Staphylococcus epidermidis biofilms have low inflammatory properties and maintain tolerance to vancomycin and penicillin after entering planktonic growth, J. Med. Microbiol. 63 (2014) 1274-1283.

[38] L. Teixeira, A.S. Botelho, S.D. Mesquita, A. Correia, F. Cerca, et al., Plasmacytoid and conventional dendritic cells are early producers of IL-12 in Neospora caninum-infected mice, Immunol. Cell Biol. 88 (2010) 79-86.

[39] P. Ferreirinha, J. Dias, A. Correia, B. Perez-Cabezas, C. Santos, et al., Protective effect of intranasal immunization with Neospora caninum membrane antigens against murine neosporosis established through the gastrointestinal tract, Immunology 141 (2014) 256-267.

[40] C. Carneiro, C. Vaz, J. Carvalho-Pereira, C. Pais, P. Sampaio, A new method for yeast phagocytosis analysis by flow cytometry, J. Microbiol. Methods 101 (2014) 56-62.

[41] D.P. Vangasseri, Z. Cui, W. Chen, D.A. Hokey, L.D. Falo Jr, et al. Immunostimulation of dendritic cells by cationic liposomes, Mol. Membr. Biol. 23 (2006) 385-395.

[42] L. Lin, A.S. Ibrahim, X. Xu, J.M. Farber, V. Avanesian, et al., Th1-Th17 cells mediate protective adaptive immunity against Staphylococcus aureus and Candida albicans infection in mice, PLoS Pathog. 5 (2009) e1000703.

[43] D. Gozalbo, V. Maneu, M.L. Gil, Role of IFN-gamma in immune responses to Candida albicans infections, Front Biosci. (Landmark Ed) 19 (2014) 1279-1290.

[44] W.L. Chaffin, Candida albicans cell wall proteins, Microbiol. Mol. Biol. Rev. 72 (2008) 495-544.

[45] A. Cassone, Development of vaccines for Candida albicans: fighting a skilled transformer, Nat. Rev. Microbiol. 11 (2013) 884-891.

[46] J. Banchereau, R.M. Steinman, Dendritic cells and the control of immunity, Nature 392 (1998) 245-252.

[47] H. Hackstein, A. Knoche, A. Nockher, J. Poeling, T. Kubin, et al., The TLR7/8 ligand resiquimod targets monocyte-derived dendritic cell differentiation via TLR8 and augments functional dendritic cell generation, Cell. Immunol. 271 (2011) 401-412.

[48] W. Chen, W. Yan, L. Huang, A simple but effective cancer vaccine consisting of an antigen and a cationic lipid, Cancer Immunol. Immunother. 57 (2008) 517 530.

[49] D. Christensen, M. Henriksen-Lacey, A.T. Kamath, T. Lindenstrom, K.S Korsholm, et al., A cationic vaccine adjuvant based on a saturated quaternary ammonium lipid have different in vivo distribution kinetics and display a distinct CD4 T cell-inducing capacity compared to its unsaturated analog, J. Control. Release 160 (2012) 468-476.

[50] D.J. Kirby, R. Kaur, E.M. Agger, P. Andersen, V.W. Bramwell, et al., Developing solid particulate vaccine adjuvants: surface bound antigen favours a humoura response, whereas entrapped antigen shows a tendency for cell mediated immunity, Curr. Drug Deliv. 10 (2013) 268-278.

[51] E. Bettelli, V.K. Kuchroo, IL-12- and IL-23-induced T helper cell subsets: birds of the same feather flock together, J. Exp. Med. 201 (2005) 169-171.

[52] G. Trinchieri, S. Pflanz, R.A. Kastelein, The IL-12 family of heterodimeric cytokines: new players in the regulation of $\mathrm{T}$ cell responses, Immunity 19 (2003) 641-644.

[53] S. Aggarwal, N. Ghilardi, M.H. Xie, F.J. de Sauvage, A.L. Gurney, Interleukin-23 promotes a distinct CD4 T cell activation state characterized by the production of interleukin-17, J. Biol. Chem. 278 (2003) 1910-1914.

[54] L. Romani, P. Puccetti, Protective tolerance to fungi: the role of IL-10 and tryptophan catabolism, Trends Microbiol. 14 (2006) 183-189.

[55] A.D. de Boer, P.W. de Groot, G. Weindl, M. Schaller, D. Riedel, et al., The Candida albicans cell wall protein Rhd3/Pga29 is abundant in the yeast form and contributes to virulence, Yeast 27 (2010) 611-624.

[56] K. Ueno, A. Okawara, S. Yamagoe, T. Naka, T. Umeyama, et al., The mannan of Candida albicans lacking beta-1,2-linked oligomannosides increases the production of inflammatory cytokines by dendritic cells, Med. Mycol. 51 (2013) 385-395

[57] H.R. Conti, S.L. Gaffen, IL-17-mediated immunity to the opportunistic fungal pathogen Candida albicans, J. Immunol. 195 (2015) 780-788.

[58] J.L. Lopez-Ribot, M. Casanova, A. Murgui, J.P. Martinez, Antibody response to Candida albicans cell wall antigens, FEMS Immunol. Med. Microbiol. 41 (2004) 187-196.

[59] S.L. Gaffen, N. Hernandez-Santos, A.C. Peterson, IL-17 signaling in host defense against Candida albicans, Immunol. Res. 50 (2011) 181-187.

[60] L. Romani, Cell mediated immunity to fungi: a reassessment, Med. Mycol. 46 (2008) 515-529.

[61] E. Ahmad, M.T. Fatima, M. Saleemuddin, M. Owais, Plasma beads loaded with Candida albicans cytosolic proteins impart protection against the fungal infection in BALB/c mice, Vaccine 30 (2012) 6851-6858.

[62] D. Pietrella, A. Rachini, M. Pines, N. Pandey, P. Mosci, et al., Th17 cells and IL-17 in protective immunity to vaginal candidiasis, PLoS ONE 6 (2011) e22770.

[63] R.J. Marijnissen, M.I. Koenders, F.L. van de Veerdonk, J. Dulos, M.G. Netea, et al. Exposure to Candida albicans polarizes a T-cell driven arthritis model towards Th17 responses, resulting in a more destructive arthritis, PLoS ONE 7 (2012) e38889.

[64] L. Romani, Immunity to fungal infections, Nat. Rev. Immunol. 11 (2011) 275

[65] W. Li, X. Hu, X. Zhang, Y. Ge, S. Zhao, et al., Immunisation with the glycolytic enzyme enolase confers effective protection against Candida albicans infection in mice, Vaccine 29 (2011) 5526-5533.

[66] G. Wang, L. Pan, Y. Zhang, Y. Wang, Z. Zhang, et al., Intranasal delivery of cationic PLGA nano/microparticles-loaded FMDV DNA vaccine encoding IL-6 elicited protective immunity against FMDV challenge, PLoS ONE 6 (2011) e27605. 
[67] A. Mahapatro, D.K. Singh, Biodegradable nanoparticles are excellent vehicle fo site directed in-vivo delivery of drugs and vaccines, J. Nanobiotechnol. 9 (2011) 55.

[68] J.J. Moon, H. Suh, M.E. Polhemus, C.F. Ockenhouse, A. Yadava, et al., Antigendisplaying lipid-enveloped PLGA nanoparticles as delivery agents for a Plasmodium vivax malaria vaccine, PLoS ONE 7 (2012) e31472.

[69] S. Beg, A. Samad, I. Nazish, R. Sultana, M. Rahman, et al., Colloidal drug delivery systems in vaccine delivery, Curr. Drug Targets 14 (2013) 123-137.

[70] S. Bhowmick, T. Mazumdar, R. Sinha, N. Ali, Comparison of liposome based antigen delivery systems for protection against Leishmania donovani, J. Control. Release 141 (2010) 199-207.

[71] H. Yu, K.P. Karunakaran, X. Jiang, C. Shen, P. Andersen, et al., Chlamydia muridarum $\mathrm{T}$ cell antigens and adjuvants that induce protective immunity in mice, Infect. Immun. 80 (2012) 1510-1518.
[72] O. Mayorga, J.E. Munoz, N. Lincopan, A.F. Teixeira, L.C. Ferreira, et al., The role of adjuvants in therapeutic protection against paracoccidioidomycosis after immunization with the P10 peptide, Front Microbiol. 3 (2012) 154.

[73] A. Chauhan, Z. Swaleha, N. Ahmad, M. Farazuddin, A. Vasco, et al., Escheriosome mediated cytosolic delivery of Candida albicans cytosolic proteins induces enhanced cytotoxic T lymphocyte response and protective immunity, Vaccine 29 (2011) 5424-5433.

[74] D. Mohanan, B. Slutter, M. Henriksen-Lacey, W. Jiskoot, J.A. Bouwstra, et al., Administration routes affect the quality of immune responses: a crosssectional evaluation of particulate antigen-delivery systems, J. Control. Release 147 (2010) 342-349. 